\title{
Accumulation of Linear Alkylbenzenesulphonate Surfactants in Sewage Sludges
}

\author{
J. McEvoy and W. Giger \\ Swiss Federal Institute for Water Resources \\ and Water Pollution Control (EAWAG), \\ Federal Institute of Technology, CH-8600 Dübendorf
}

Linear alkylbenzenesulphonates (LAS) are the major synthetic surfactants currently manufactured. Their global production in 1982 was estimated at $1.1 \times$ $10^{6}$ metric tons which accounted for $28 \%$ of all synthetically produced surfactants [1]. Commercial LAS surfactants are characteristically complex mixtures [2] which are composed of components having alkyl chains of $\mathrm{C}_{10}$ to $\mathrm{C}_{15}$ with $\mathrm{C}_{11}, \mathrm{C}_{12}$, and $\mathrm{C}_{13}$ usually predominant. LAS are extensively employed in both household and industry as cleaning agents, and have wide application in textile, paper, pulp and paint processing. The heavy usage of these surfactants and their subsequent release into the wastewater system prompted this study into the occurrence of LAS in sewage sludges and their behaviour and fate during sewage sludge treatment. In Switzerland approximately $70 \%$ of the sewage sludge (corresponding to 110000 metric tons of dry sludge year ${ }^{-1}$ ) is applied to agricultural land. Hence the report that LAS can make up $5 \%$ of the fulvic acid fraction in sewage sludge [3] is of considerable concern.

For this study, sludge samples (Table 1) were collected from eight Swiss sewage treatment plants which have basically similar inputs from catchment areas including both household and industry. All of the sludges were digested anaerobically except for the sample from Eglisau, which was aerobically stabilized. The three samples from Altenrhein represent fresh sludge (A), sludge digested under thermophilic, an- aerobic conditions (B; 15 days, $55^{\circ} \mathrm{C}$ ) and under mesophilic, anaerobic conditions $\left(\mathrm{C} ; 15\right.$ days, $\left.35^{\circ} \mathrm{C}\right)$. Samples $\mathrm{B}$ and $\mathrm{C}$ were also treated under aerobic, thermophilic conditions $\left(15 \mathrm{~h}, 60^{\circ} \mathrm{C}\right)$ prior to anaerobic digestion. The $\mathrm{Al}$ tenrhein sludges were sampled in such a manner that samples $B$ and $C$ can be reasonably well related to sludge sample A.

Numerous studies have been concerned with LAS measurements in aqueous samples [4] but less attention has been focused on LAS in sewage sludges [3]. Most investigations involve analyses based on ion-pairing of LAS with methylene blue and subsequent spectrophotometric determination. However, such methods are not unambiguously specific to LAS, and no informa- tion about the individual LAS compounds is obtained. Our work was based on a method used by Hon-nami and Hanya [5], who reported LAS concentrations in Japanese rivers. We extracted LAS from wet sewage sludge into chloroform following ion-pairing with methylene blue. The LAS fraction was then isolated from this extract by thin-layer chromatography on silica using dichloromethane as the mobile phase. A blue band corresponding to the methylene blue-active substances was collected and the components extracted with methanol. The contents were reacted with phosphorus pentachloride to form the linear alkylbenzenesulphonyl chlorides. Subsequent analyses were performed by high resolution gas chromatography with flame

Table 1. Total linear alkylbenzenesulphonate concentrations and relative distribution of homologous components in digested sewage sludges (tr: trace amount)

\begin{tabular}{llllllll}
\hline $\begin{array}{l}\text { Origin of } \\
\text { sludge sample }\end{array}$ & $\begin{array}{l}\text { Total LAS } \\
\text { concentration } \\
{\left[\mathrm{g} \mathrm{kg}^{-1} \text { dry matter] }\right.}\end{array}$ & \multicolumn{5}{c}{ Distribution of homologous components [\%] } \\
\cline { 3 - 8 } & $\mathrm{C}_{10}$ & $\mathrm{C}_{11}$ & $\mathrm{C}_{12}$ & $\mathrm{C}_{13}$ & $\mathrm{C}_{14}$ & $\mathrm{C}_{15}$ \\
\hline Affoltern & 3.5 & 4 & 26 & 45 & 21 & 4 & $\mathrm{tr}$ \\
Bassersdorf & 5.4 & 4 & 35 & 42 & 16 & 3 & $\mathrm{tr}$ \\
Eglisau $^{\mathrm{b}}$ & 2.9 & 5 & 31 & 41 & 17 & 6 & $\mathrm{tr}$ \\
Uster & 4.5 & 4 & 30 & 42 & 19 & 5 & $\mathrm{tr}$ \\
Wetzikon & 11.9 & 2 & 27 & 40 & 25 & 5 & 1 \\
Winterthur & 3.1 & 4 & 34 & 40 & 16 & 6 & $\mathrm{tr}$ \\
Zürich-Glatt & 7.1 & 3 & 28 & 44 & 20 & 5 & $\mathrm{tr}$ \\
Altenrhein A & 5.1 & 5 & 27 & 40 & 21 & 6 & 1 \\
Altenrhein B & 6.6 & 7 & 27 & 39 & 20 & 6 & 1 \\
Altenrhein C & 6.1 & 6 & 26 & 39 & 21 & 7 & 1 \\
\hline
\end{tabular}

a $\mathrm{C}_{n}$ : LAS with $n$ carbon atoms in the alkyl substituent

b Aerobically stabilized 


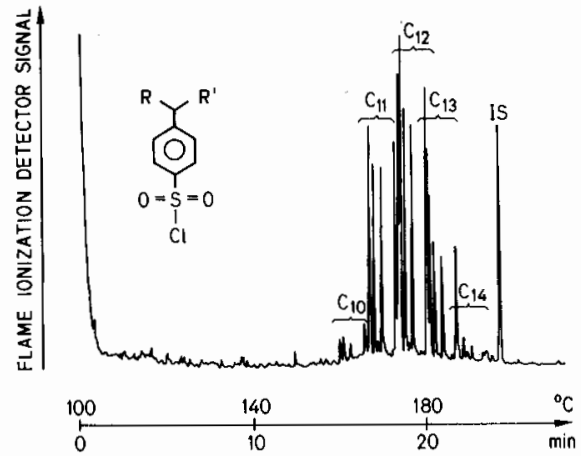

Fig. 1. High-resolution gas chromatogram of linear alkylbenzenesulphonyl chlorides from Altenrhein thermophilic anaerobically digested sewage sludge $\left(R+R^{\prime}+1=C_{10}\right.$ to $\mathrm{C}_{14}$ ). IS internal standard, 4-(1-ethyldodecyl)benzenesulphonyl chloride. Gas chromatographic conditions: glass capillary column coated with PS 255 immobilized stationary phase $(19 \times 0.31 \mathrm{~mm}$ i.d. $)$, hydrogen carrier gas, splitless injection at room temperature, $4^{\circ} \mathrm{C} \mathrm{min}^{-1}$ from 100 to $220^{\circ} \mathrm{C}$, flame ionization detector

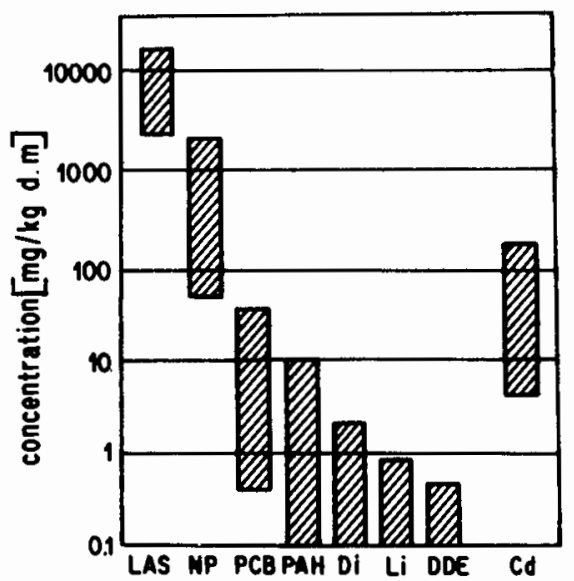

Fig. 2. Concentrations of potentially toxic chemicals in stabilized sewage sludge (mg kg ${ }^{-1}$ dry matter). LAS linear alkylbenzenesulphonates; $N P$ 4-nonylphenols; $P C B$ polychlorinated biphenyls; $P A H$ polynuclear aromatic hydrocarbons; $D i$ dieldrine; $L i$ lindane; $D D E$ 1,1-bis-(4-chlorophenyl)2,2-dichloroethene; $C d$ cadmium

ionization detection and directly coupled mass spectrometry using glass capillary columns coated with immobilized nonpolar stationary phases [6]. Details of the experimental procedures and of the obtained analytical results are reported elsewhere [7].

The sewage sludges contained a range of LAS components with alkyl chains of 10 to 14 carbon atoms as major con- stituents, and all secondary substituted LAS isomers were detected. Figure 1 shows as a typical example the gas chromatogram of LAS (as their sulphonyl chlorides) isolated from sewage sludge after anaerobic, thermophilic digestion at the Altenrhein treatment plant. Total LAS concentrations and relative distributions of LAS homologues found in the sewage sludges are given in Table 1.

The concentrations of LAS determined in the sludges represent up to $1.2 \%$ of the total dry matter or approximately 2 to $5 \%$ of the total organic carbon. This confirms the tentative results reported earlier [3] where LAS was determined in sludge-derived fulvic acid material by semi-specific infrared spectroscopy. These levels of LAS are viewed with concern, as they are significantly greater than that of the toxic pollutant 4-nonylphenol in these same samples. Figure 2 gives a comparison of the concentrations of LAS and of other toxic chemicals reported in sewage sludges [8]. The high LAS concentrations are surprising, as it is known that their biodegradation is efficient in aerobic biological wastewater treatment [9]. However, LAS surfactants exhibit both lipophobic and lipophilic properties and thus adsorb to particles which are sedimented as sewage sludge. It has been shown [10] that adsorption of LAS onto minerals in soil inhibits their degradation, and the same appears to be true when LAS are adsorbed to sewage sludge. The concentrations of LAS in sludges from Altenrhein are very similar both before and after digestion of the sludge (Table 1). The implication is that no significant biodegradation of LAS has occurred during anaerobic digestion. This preliminary conclusion is supported by the virtually identical distributions of the various isomers and homologues in the Altenrhein sludges, both before and after digestion. This is significant as the length of the alkyl chain and the position of phenyl attachment to the alkyl chain influence the rate of LAS biodegradation [9].

The environmental significance of this study is that remarkably high concentrations of LAS occur in sewage sludges. LAS are, according to conventional tests, an order of magnitude less toxic than 4-nonylphenol [11], but there is approximately an order of magnitude more LAS present. In con- trast to the study of 4-nonylphenol in sewage sludges, the investigation reported here is concerned with unaltered surfactants; no determination of partially degraded metabolites of LAS was attempted. Further research into the transport mechanisms and pathways of LAS during sewage and sewage sludge treatment is necessary. It also appears that investigations are warranted into the concentrations of LAS in soils to which sewage sludge has been applied and into their impact on soil chemistry and biota. Are LAS efficiently degraded under the aerobic soil conditions or can they be taken up by plants?

Previous research into sewage sludges has been mainly devoted to measuring the concentrations of inorganic contaminants (heavy metals) and their impact on the environment. It seems necessary to make efforts to screen sewage sludges for elevated concentrations of organic chemicals which are due to anthropogenic activities and which might have adverse effects when the sludges are disposed of.

We wish to thank P.H. Brunner and $H$. Motschi for helpful discussions and K. Grob, G. Grob and C. Schaffner for supplying glass capillary columns. This project was funded by the Swiss National Science Foundation (Nationales Forschungsprogramm 7D on Organic Contaminants in Sewage Sludge).

Received March 29 and April 22, 1985

1. Werdelmann, B.W, in: Proc. World Surfactants Congr., Vol. I, p. 3. Gelnhausen: Kürle

2. Feighner, G.C., in: Anionic Surfactants, part I, p. 253 (W.M. Linfield, ed.). New York: Dekker 1976

3. Holtzclaw, K.M., Sposito, G.: Soil Sci. Soc. Am. J. 42, 607 (1978); Schaumberg, G.D., et al.: ibid. 46, 310 (1982)

4. Llenado, R.A., Neubecker, T.A.: Anal. Chem. 55, 93R (1983); Kunkel, E.: Tenside Deterg. 18, 301 (1981)

5. Hon-nami, H., Hanya, T.: J. Chromatogr. $161,205(1978)$

6. Grob, K., et al.: ibid. 244, 197 (1982)

7. McEvoy, J., Giger, W.: Environ. Sci. Technol. (submitted)

8. Giger, W., Brunner, P.H., Schaffner, C.: Science 225, 623 (1984); Schaffner, C., Brunner, P.H., Giger, W., in: Processing and Use of Sewage Sludge, p. 168 (P. 
L'Hermite, H. Ott, eds.). Dordrecht: Reidel 1984; Lester, J.N., in: Environmental Effects of Organic and Inorganic Contaminants in Sewage Sludge, p. 3 (R.D. Davis, G. Hucker, P. L'Hermite, eds.). Dordrecht: Reidel 1983
9. Swisher, R.D.: Surfactant Biodegradation. New York: Dekker 1970; Swisher, R.D.: Tenside Deterg. 18, 59 (1981); Gledhill, W.E.: Appl. Microbiol. 30, 922 (1975); Divo, C., Cardini, G.: Tenside Deterg. 17, 30 (1980)
10. Inoue, K., Kaneko, K., Yoshida, M.: Soil Sci. Plant Nutr. 24, 91 (1978)

11. McLeese, D.W., et al.: Chemosphere 10, 723 (1981); Divo, C. : Riv. Ital. Sostanze Grasse 53, 88 (1976); Schöberl, P., Kunkel, E.: Tenside Deterg. 14, 293 (1977) 